\title{
FOXP1-related intellectual disability syndrome: a recognisable entity
}

\author{
Ilse Meerschaut, ${ }^{1,2}$ Daniel Rochefort, ${ }^{3}$ Nicole Revençu, ${ }^{4}$ Justine Pètre, ${ }^{4}$ \\ Christina Corsello, ${ }^{3}$ Guy A Rouleau, ${ }^{3}$ Fadi F Hamdan, ${ }^{5}$ Jacques L Michaud, ${ }^{5}$ \\ Jenny Morton, ${ }^{6}$ Jessica Radley, ${ }^{6}$ Nicola Ragge, ${ }^{6}$ Sixto García-Miñaúr, ${ }^{7}$ \\ Pablo Lapunzina, ${ }^{7}$ Maria Palomares Bralo, ${ }^{7}$ Maria Ángeles Mori, ${ }^{7}$ Stéphanie Moortgat, ${ }^{8}$ \\ Valérie Benoit, ${ }^{8}$ Sandrine Mary, ${ }^{8}$ Nele Bockaert, ${ }^{2}$ Ann Oostra, ${ }^{2}$ Olivier Vanakker, ${ }^{1,2}$ \\ Milen Velinov ${ }^{9}$ Thomy JL de Ravel, $^{10}$ Djalila Mekahli, ${ }^{11}$ Jonathan Sebat, ${ }^{12}$ \\ Keith K Vaux, ${ }^{13}$ Nataliya DiDonato, ${ }^{14}$ Andrea K Hanson-Kahn, ${ }^{15}$ Louanne Hudgins, ${ }^{15}$ \\ Bruno Dallapiccola, ${ }^{16}$ Antonio Novelli, ${ }^{16}$ Luigi Tarani, $^{17}$ Joris Andrieux, ${ }^{18}$ \\ Michael J Parker, ${ }^{19}$ Katherine Neas, $^{20}$ Berten Ceulemans, ${ }^{21}$ An-Sofie Schoonjans, ${ }^{21}$ \\ Darina Prchalova, ${ }^{22}$ Marketa Havlovicova, ${ }^{22}$ Miroslava Hancarova, ${ }^{22}$ \\ Magdalena Budisteanu, ${ }^{23}$ Annelies Dheedene, ${ }^{1}$ Björn Menten, ${ }^{1}$ Patrick A Dion, ${ }^{3}$ \\ Damien Lederer, ${ }^{8}$ Bert Callewaert ${ }^{1,2}$
}

\begin{abstract}
- Additional material is published online only. To view please visit the journal online (http://dx.doi.org/10.1136/ jmedgenet-2017-104579)
\end{abstract}

For numbered affiliations see end of article.

\section{Correspondence to} Dr Bert Callewaert, Center for Medical Genetics, Ghent University Hospital, De Pintelaan 185, 9000 Gent, Belgium; Bert. Callewaert@Ugent.be

Received 31 January 2017 Revised 3 May 2017

Accepted 11 May 2017 Published Online First 22 July 2017

\section{CrossMark}

To cite: Meerschaut I, Rochefort D, Revençu N, et al. J Med Genet

2017:54:613-623.

\section{ABSTRACT}

Background Mutations in forkhead box protein P1 (FOXP1) cause intellectual disability (ID) and specific language impairment (SLI), with or without autistic features (MIM: 613670). Despite multiple case reports no specific phenotype emerged so far.

Methods We correlate clinical and molecular data of 25 novel and 23 previously reported patients with FOXP1 defects. We evaluated FOXP1 activity by an in vitro luciferase model and assessed protein stability in vitro by western blotting.

Results Patients show ID, SLI, neuromotor delay (NMD) and recurrent facial features including a high broad forehead, bent downslanting palpebral fissures, ptosis and/or blepharophimosis and a bulbous nasal tip. Behavioural problems and autistic features are common. Brain, cardiac and urogenital malformations can be associated. More severe ID and NMD, sensorineural hearing loss and feeding difficulties are more common in patients with interstitial $3 p$ deletions (14 patients) versus patients with monogenic FOXP1 defects (34 patients). Mutations result in impaired transcriptional repression and/or reduced protein stability.

Conclusions FOXP1-related ID syndrome is a recognisable entity with a wide clinical spectrum and frequent systemic involvement. Our data will be helpful to evaluate genotype-phenotype correlations when interpreting next-generation sequencing data obtained in patients with ID and/or SLI and will guide clinical management.

\section{INTRODUCTION}

Intellectual disability (ID) and speech and language disorders are common problems in the paediatric population and frequent reasons for encounter with child neurologists and clinical geneticists. They cover a wide range of conditions with heterogeneous phenotypes, making gestalt diagnosis complicated and challenging. In the majority of patients, no molecular defect has been identified thus far, arguing for a genetic heterogeneous and probably multifactorial aetiology. ${ }^{1-4}$

Meanwhile, over 700 genes have been identified in both isolated ID and ID-associated disorders, and several genes have been associated with speech and language disorders, including FOXP1, FOXP2, SHANK3 and TM4SF20. ${ }^{145}$ Additional loci for specific language impairment (SLI), a specific form of speech and language disorders defined by an isolated delayed or absent language acquisition that may however be associated with autism and/or oromotor dyspraxia, have been mapped to chromosomal regions $16 \mathrm{q}$ (SLI1; OMIM\#606711)，19q (SLI2; OMIM\#606712), 13q21 (SLI3; OMIM\#607134) and 7q35-q36 (SLI4; OMIM\#612514).

The first gene implicated in the pathogenesis of developmental speech and language disorders was FOXP $2 .{ }^{6}$ Later on, similar expression patterns of FOXP2 and FOXP1 in songbird and human brain suggested a functional relationship. ${ }^{7}$ Since then, several case reports have confirmed FOXP1 defects in language impairment other than verbal dyspraxia, ${ }^{8} 9$ including both monogenic FOXP1 mutations and more extensive $3 p$ chromosomal deletions encompassing FOXP1. However, until now, no specific phenotype has emerged. The absence of a clear 'gestalt' in monogenic causes of SLI, including FOXP1-related SLI, complicates the work-up and delays the diagnosis.

With the introduction of array comparative genome hybridisation (arrayCGH) and next-generation sequencing (NGS) in clinical practice, the concept of reverse genetics allows to identify a recurrent phenotype in patients with similar molecular defects, delineating novel conditions and 
providing useful information for prognosis, management guidelines and recurrence risk to other family members.

FOXP1 encodes forkhead box protein P1, which belongs to the family of the winged helix/forkhead transcription factors that regulate embryogenesis and maintenance of differentiated tissues through transcriptional repression. ${ }^{10}{ }^{11}$ FOXP1 is widely expressed. ${ }^{12-17}$ Hence, reduced FOXP1 functioning may perturb the development of multiple organ systems.

We report on the molecular and clinical data of 25 novel patients with a FOXP1 defect and compare the data with 23 previously reported patients. This comprehensive description evidences a recognisable 'gestalt' for FOXP1-related ID syndrome. Based on the relative frequent occurrence of non-neurological anomalies, we provide recommendations for clinical management and follow-up. We further show that both missense and premature truncation mutations reduce FOXP1 repression activity and/or interfere with protein stability.

\section{METHODS}

\section{Patients}

All patients were evaluated by experienced clinical geneticists and recruited through direct referral or through the Decipher website. Patient 19 (Decipher 252324) was already published by Thevenon et $a l^{18}$ although a more detailed phenotypic description is presented here. Previously published patients with FOXP1 mutations were identified through a National Center for Biotechnology Information (NCBI) PubMed literature search (www.ncbi.nlm.nih.gov/pubmed). ${ }^{9}$ 18-29 We excluded the four patients reported by Chang et $a l^{12}$ and Srivastava $e t a l^{30}$ because of the unavailability of phenotypic data. We also excluded patients with interstitial $3 \mathrm{p}$ deletions if the precise chromosomal breakpoints were not provided and therefore the involvement of FOXP1 unknown.

The study was approved by the Ethics Committee of the Ghent University Hospital. For the publication of clinical and molecular data, we obtained informed consent from all individuals or their legal representatives. For publication of clinical pictures, we obtained a specific consent.

\section{Phenotypic analysis}

A clinical summary, photographs and a checklist were provided by the referring clinicians. To reduce interobserver variability, all data were re-evaluated by IM and BCa. Missing data were excluded from statistical analyses. Subgroup analysis, comparing patients with $3 \mathrm{p}$ deletions and monogenic FOXP1 defects, and patients with FOXP1 deletions or truncating mutations (nonsense, frameshift and splice site mutations) and FOXP1 missense mutations, was performed using Fisher's exact tests (SPSS Statistics V.22).

\section{Molecular analysis}

Molecular analysis was performed at each referring centre with varying methodologies for arrayCGH analysis, direct Sanger sequencing and NGS of ID gene panels. All NGS detected FOXP1 mutations were confirmed by Sanger sequencing. Sequences were compared with the wild-type sequence as submitted to NM_032682.5 (Ensembl Accession number ENST00000318789.4). Nucleotides were numbered starting from the first base of the initiation codon (ATG) of the cDNA reference sequence. Amino acid residues are numbered from the first methionine residue of the reference sequence. CNVs were mapped against the human genome build hg19/GRCh37.

\section{Functional analysis}

\section{Luciferase assay}

To evaluate transcriptional repression activity, we used a standard luciferase assay. ${ }^{9} 2326$ Mutations were introduced into the full length coding sequence of FOXP1 longest isoform (FOXP1a; obtained from Kazusa DNA Research Institute, Kisarazu, Japan) and subcloned into the mammalian expression vector pcDNA4His (Invitrogen). HEK293 cells were then cotransfected using Fugene 6 (Roche), in 24-well plates, with $400 \mathrm{ng}$ of pcDNA4His without an insert or containing the wild-type FOXP1 (wt-FOXP1) or the mutant FOXP1 cDNA, along with $50 \mathrm{ng}$ of pGL3-promoter construct (Promega) (in which the SV40 promoter drives a firefly luciferase reporter). To normalise for transfection efficiency and variation in cell number, cells were also cotransfected with $50 \mathrm{ng}$ of a Renilla luciferase construct (pRL-TK; Promega) driven by the HSV-thymidine kinase promoter which is not affected by FOXP1. Cells were lysed 48 hours after transfection. Firefly and Renilla luciferase activities were quantified using the Synergy H4 Hybrid Multiplate Reader (BioTek). Protein expression was verified by western blotting (see below). Student's t-test was performed to evaluate statistical significance.

\section{Western blotting}

Expression of the different exogenously expressed proteins was evaluated using standard western blotting. To enable monitoring and detection of FOXP1, we fused it to an n-terminal tag (Xpress) and used Xpress Monoclonal Antibody (Thermo Fisher Scientific) for detection, thereby avoiding simultaneous detection of endogenous FOXP1. Ten micrograms of total protein were loaded per lane of a $12 \%$ acrylamide gel (Bio-Rad). Transfer onto a low fluorescence polyvinylidene difluoride (PVDF) membrane was done using turbo blot.

\section{Splicing efficiency}

Splice site mutations were tested in the pSPL3 splicing vector. $^{31} 32$ The FOXP1 exons flanked by $200 \mathrm{bp}$ of intronic sequence containing the putative splice mutation were cloned in between two b-globin exons. HEK293 cells were transfected with these constructs and RNA was collected 48 hours post-transfection. Splicing was analysed by sequencing the RT-PCR fragment generated by the fused b-globin mini-gene.

\section{RESULTS}

\section{Molecular characteristics}

The molecular data of 25 novel and 23 previously reported patients are shown in figure 1 and see online supplementary table 1. In our cohort, all defects originated de novo (22/22) (in three patients the analysis of parents was not possible). Six patients have an interstitial $3 p$ deletion (6/25) affecting more proximally and/or more distally located genes with sizes of the deleted region ranging from $\sim 3 \mathrm{Mb}$ to $\sim 6 \mathrm{Mb}$. Nineteen patients have a monogenic FOXP1 defect (19/25), including five partial FOXP1 deletions $(5 / 19)(\sim 120 \mathrm{~kb}$ to $\sim 630 \mathrm{~kb})$ and 14 point mutations (14/19), comprising nonsense (6/14), missense (2/14), frameshift $(3 / 14)$ or splice site $(3 / 14)$ alterations. Three patients harbour the c. $1573 \mathrm{C}>\mathrm{T}, \mathrm{p}$. $\left(\operatorname{Arg} 525^{*}\right)$ mutation, previously reported by Hamdan et al. ${ }^{9}$

Comparable, all previously reported cases have de novo (19/19) defects (data were missing for four patients), including extended $3 \mathrm{p}$ deletions $(8 / 23)(\sim 800 \mathrm{~kb}$ to $\sim 27.2 \mathrm{Mb})$, whole FOXP1 deletions $(1 / 15)(\sim 200 \mathrm{~kb}$ to $\sim 1 \mathrm{Mb})$, partial 


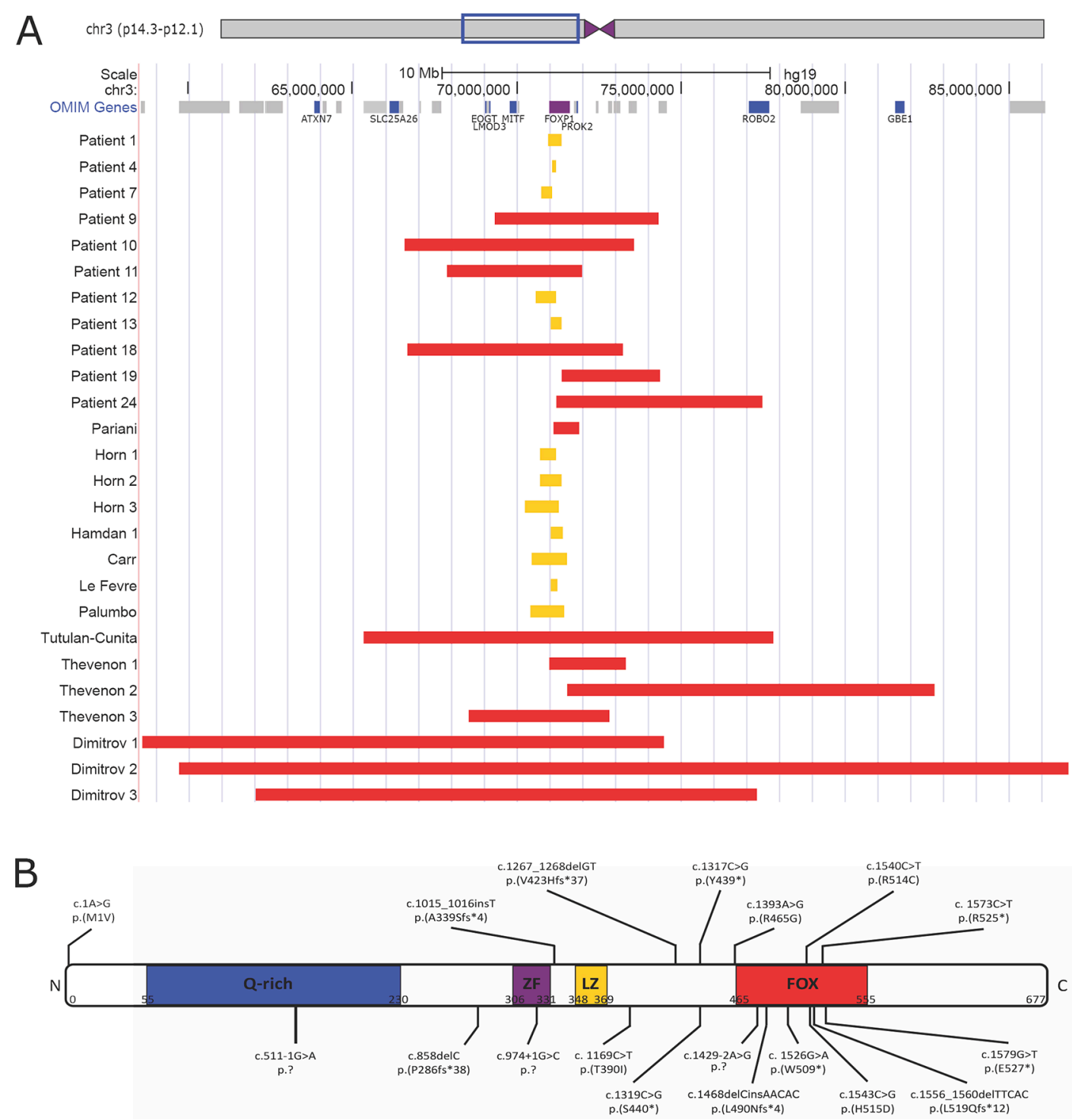

Figure 1 Molecular data of 25 novel and 23 previously reported patients with FOXP1 defects. (A) CNVs affecting FOXP1. Interstitial 3p deletions encompassing FOXP1 are depicted in red, CNVs restricted to FOXP1 are shown in yellow. (B) Small indels and point mutations identified in FOXP1. Previously reported mutations are shown above the schematic representation of the FOXP1 protein, while novel mutations identified in this study are shown below. Four patients harbour the c.1573C>T, p.(Arg525*) mutation. (Q-rich, glycine-rich domain; ZF, zinc finger domain; LZ, leucine zipper domain; and FOX, DNA-binding forkhead box domain).

FOXP1 deletions (6/15) and seven point mutations (7/15) (2 nonsense, 3 missense and 2 frameshift). One patient has a balanced chromosomal rearrangement with breakpoints in 3 p13 (affecting FOXP1) and 10q21.2 (1/15).

Most pathogenic FOXP1 variants result in premature truncation (10/18). Missense mutations (5/18) and splice site mutations (3/18) are present in a minority of the patients. Figure 1B illustrates that nonsense mutations, frameshift mutations and splice site mutations appear throughout the whole protein, while all but one missense mutations are located in or close to the DNA-binding FOX domain.

As shown in figure 2, further functional evaluation of p.Arg525*, p.Trp509*, p.His515Asp and p.Thr390Ile mutant proteins shows that FOXP1-Arg525\% and FOXP1-Trp509* (both stably expressed from plasmid cDNA vectors) fail to reduce luciferase levels as compared with wt-FOXP1 $(\mathrm{p}<0.001)$, indicating that both truncating mutations impair FOXP1s ability to repress the SV40 promoter. The missense mutation FOXP1-His515Asp (also stably expressed in vitro) maintains some residual repressor activity $(\mathrm{p}<0.005)$, while FOXP1-Thr390Ile (which has limited protein expression in vitro) has rather normal repressor activity.

Furthermore, we evaluated the effects of FOXP1 c. $974+1 G>C, \quad$ c. $1429-2 A>G$ and c.551-1G $>$ A mutations on splicing. Failed sequencing of the RT-PCR fragment of the c.974+1G $>C$ donor splice site mutation and the c.1429-2A $>\mathrm{G}$ acceptor splice site mutation could result from nonsense-mediated mRNA decay or exon skipping. The c. $974+1 G>C$ mutation resulted in normal splicing, although with a lower splicing efficiency. For the c. 1429-2A $>$ G mutation, the exon is skipped in $100 \%$, compared with $50 \%$ in wt-FOXP1 in this system. The c.551-1G>A acceptor splice site mutation results in alternative splicing skipping $6 \mathrm{bp}$ of the exon (resulting in deletion of two glutamine residues) (data not shown). 
A

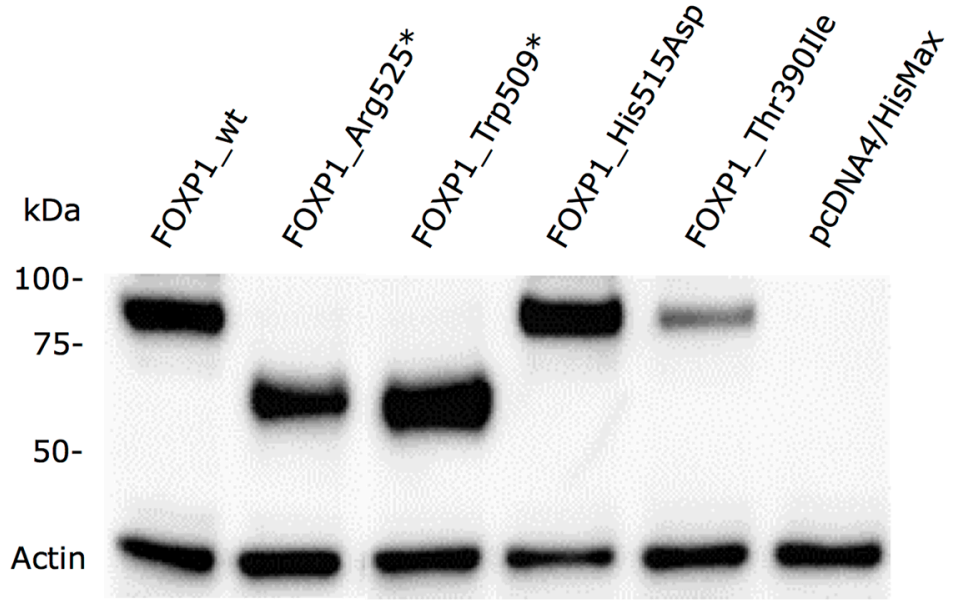

B

\section{Relative luciferase activity (\%)}

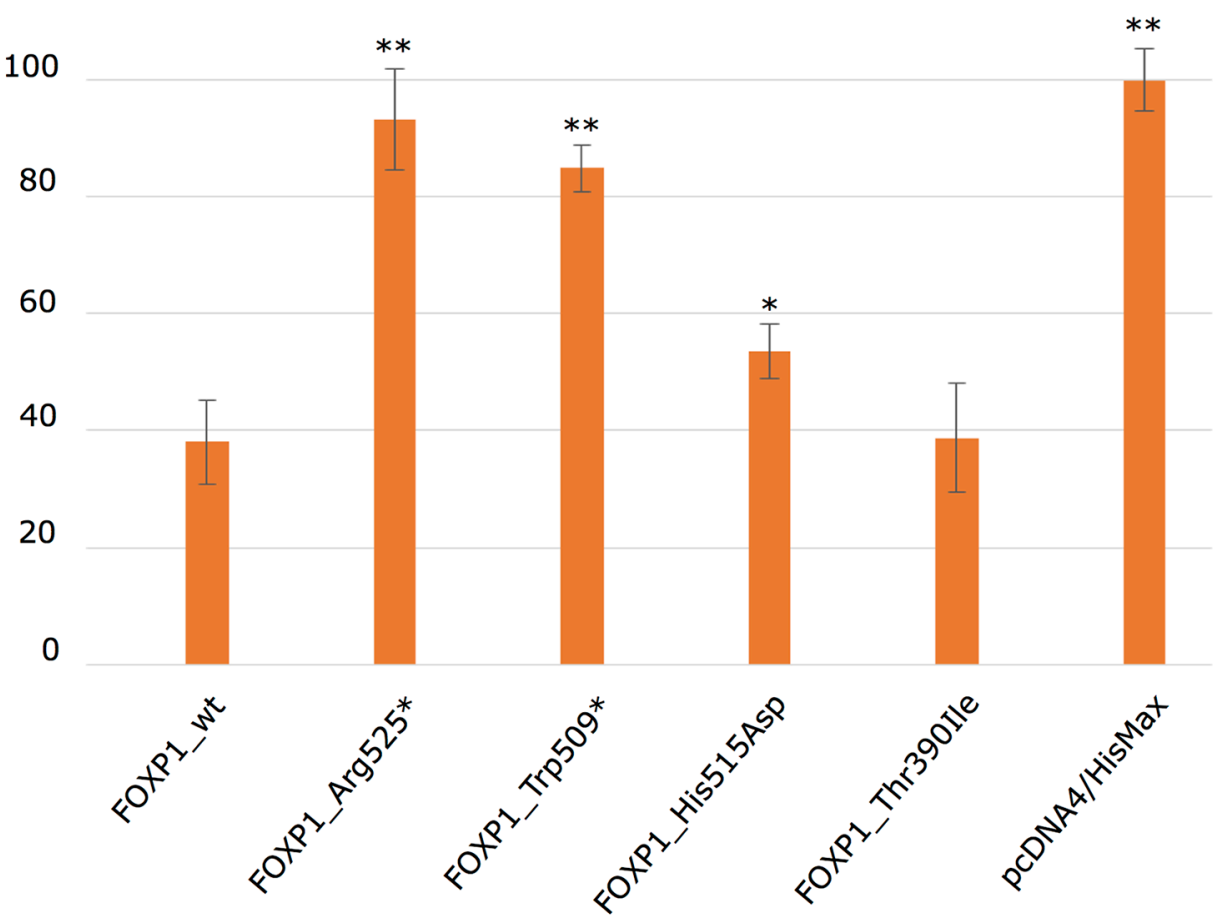

Figure 2 Functional analysis in selected group of FOXP1 mutations. (A) Results of western blot evaluating the effects of FOXP1 variants on protein expression from cDNA plasmid vectors. FOXP1-p.Arg525*, p.Trp509* and p.His515Asp are stably expressed, while p.Thr390lle results in decreased protein expression. The detection of endogenous produced beta actin insured equivalent loading of protein in all western blot tracks. (B) Luciferase reporter assay assessing the impact of the p.Arg525*, p.Trp509*, p. His515Asp and p.Thr390lle mutations on FOXP1 transactivation activity in transfected HEK293 cells. Wild-type FOXP1 and FOXP1-Thr390lle significantly inhibited pGL3-promoter (SV40) transcriptional activity $(p<0.001)$ as compared with empty vector (pcDNA4)-transfected cells only (comparisons for each pair using Student's t-test). In contrast, FOXP1-Arg525* and FOXP1-Trp509* failed to repress the pGL3-promoter activity $\left({ }^{* *} p<0.001\right)$. FOXP1-His515Asp had a reduced repression activity compared with FOXP1 $\left.{ }^{*} p<0.005\right)$. Results (mean of four independent experiments, each performed in triplicate) are shown as relative firefly luciferase activity, which is driven by SV40 promoter, normalised with Renilla luciferase and driven by herpes simplex virus thymidine kinase (HSV-TK) promoter activity. The control signal value was obtained with cells transfected with the empty expression vector (pcDNA4/HisMax) and both pGL3-promoter (firefly luciferase) and pRL-TK (Renilla luciferase) constructs.

\section{Phenotypic characteristics}

The phenotypic characteristics of all novel and previously reported patients are summarised in table 1 . For extended clinical data see online supplementary table 2 .
Demographic characteristics

Patients originate from Belgium (9/25), France (1/25), Germany $(1 / 25)$, the UK (5/25), Spain (3/25), Italy (1/25), the Czech Republic (1/25), the USA (3/25) and New Zealand (1/25). 
Table 1 Overview of clinical features in FOXP1 patients

\begin{tabular}{|c|c|c|c|c|c|c|}
\hline Characteristics & \multicolumn{2}{|c|}{ Our cohort } & \multicolumn{2}{|c|}{ Literature } & \multicolumn{2}{|c|}{ Total } \\
\hline Sex (male:female) & \multicolumn{2}{|c|}{$20: 5$} & \multicolumn{2}{|c|}{$14: 9$} & \multicolumn{2}{|c|}{$34: 14$} \\
\hline Mild/moderate motor delay & $15 / 24$ & $63 \%$ & $15 / 21$ & $71 \%$ & $30 / 45$ & $67 \%$ \\
\hline Severe motor delay & $7 / 24$ & $29 \%$ & $6 / 21$ & $29 \%$ & $13 / 45$ & $29 \%$ \\
\hline Mild/moderate intellectual disability & $15 / 24$ & $63 \%$ & $13 / 19$ & $68 \%$ & $28 / 43$ & $65 \%$ \\
\hline Severe intellectual disability & $8 / 24$ & $33 \%$ & $6 / 19$ & $32 \%$ & $14 / 43$ & $33 \%$ \\
\hline Speech and language delay & $23 / 23$ & $100 \%$ & $19 / 19$ & $100 \%$ & $42 / 42$ & $100 \%$ \\
\hline Expressive language delay & $18 / 19$ & $95 \%$ & $11 / 11$ & $100 \%$ & $29 / 30$ & $97 \%$ \\
\hline Articulation problems & $9 / 11$ & $82 \%$ & $10 / 10$ & $100 \%$ & $19 / 21$ & $90 \%$ \\
\hline Poor grammar & $5 / 7$ & $71 \%$ & $4 / 4$ & $100 \%$ & $9 / 11$ & $82 \%$ \\
\hline Oromotor dysfunction & $10 / 17$ & $59 \%$ & $4 / 10$ & $40 \%$ & $14 / 27$ & $52 \%$ \\
\hline Behavioural difficulties & $12 / 19$ & $63 \%$ & $10 / 13$ & $77 \%$ & $22 / 32$ & $69 \%$ \\
\hline Autistic features & $14 / 20$ & $70 \%$ & $10 / 12$ & $83 \%$ & $24 / 32$ & $75 \%$ \\
\hline Abnormal tonicity & $14 / 21$ & $67 \%$ & $12 / 14$ & $86 \%$ & $26 / 35$ & $74 \%$ \\
\hline Spasticity/contractures & $10 / 19$ & $53 \%$ & $8 / 10$ & $80 \%$ & $18 / 29$ & $62 \%$ \\
\hline Abnormal reflexes & $3 / 17$ & $18 \%$ & $5 / 8$ & $63 \%$ & $8 / 25$ & $32 \%$ \\
\hline Seizures & $3 / 22$ & $14 \%$ & $4 / 11$ & $36 \%$ & $7 / 33$ & $21 \%$ \\
\hline Abnormal brain imaging & $11 / 23$ & $48 \%$ & $10 / 14$ & $71 \%$ & $21 / 37$ & $57 \%$ \\
\hline Abnormal electroencephalography & $2 / 12$ & $17 \%$ & $2 / 9$ & $22 \%$ & $4 / 21$ & $19 \%$ \\
\hline Failure to thrive & $8 / 22$ & $36 \%$ & $7 / 15$ & $47 \%$ & $15 / 37$ & $41 \%$ \\
\hline Feeding difficulties & $16 / 24$ & $67 \%$ & $8 / 11$ & $73 \%$ & $24 / 35$ & $69 \%$ \\
\hline Obesity & $0 / 23$ & $0 \%$ & $2 / 11$ & $18 \%$ & $2 / 34$ & $6 \%$ \\
\hline Broad, prominent forehead & $23 / 24$ & $96 \%$ & $11 / 15$ & $73 \%$ & $34 / 39$ & $87 \%$ \\
\hline Frontal hair upsweep & $10 / 24$ & $42 \%$ & $5 / 14$ & $36 \%$ & $15 / 38$ & $39 \%$ \\
\hline Hypertelorism & $11 / 24$ & $46 \%$ & $9 / 16$ & $56 \%$ & $20 / 40$ & $50 \%$ \\
\hline Downslanting palpebral fissures & $14 / 24$ & $58 \%$ & $7 / 14$ & $50 \%$ & $21 / 38$ & $55 \%$ \\
\hline Bent palpebral fissures & $5 / 16$ & $31 \%$ & - & - & $5 / 16$ & $31 \%$ \\
\hline Ptosis & $16 / 24$ & $67 \%$ & $6 / 9$ & $67 \%$ & $22 / 33$ & $67 \%$ \\
\hline Blepharophimosis & $4 / 24$ & $17 \%$ & $1 / 11$ & $9 \%$ & $5 / 35$ & $14 \%$ \\
\hline Short nose & $17 / 24$ & $71 \%$ & $10 / 15$ & $67 \%$ & $27 / 39$ & $69 \%$ \\
\hline Broad nose tip & $19 / 24$ & $79 \%$ & $9 / 15$ & $60 \%$ & $28 / 39$ & $72 \%$ \\
\hline Pronounced nasolabial folds & $10 / 24$ & $42 \%$ & $1 / 9$ & $11 \%$ & $11 / 33$ & $33 \%$ \\
\hline Wide mouth with full lips & $14 / 24$ & $58 \%$ & $2 / 14$ & $14 \%$ & $16 / 38$ & $42 \%$ \\
\hline Pronounced vermilion border & $16 / 22$ & $73 \%$ & - & - & $16 / 22$ & $73 \%$ \\
\hline Downturned corners of the mouth & $14 / 24$ & $58 \%$ & $4 / 10$ & $40 \%$ & $18 / 34$ & $53 \%$ \\
\hline Open mouth & $12 / 20$ & $60 \%$ & $6 / 9$ & $67 \%$ & $18 / 29$ & $62 \%$ \\
\hline Prominent chin & $9 / 22$ & $41 \%$ & - & - & $9 / 22$ & $41 \%$ \\
\hline Horizontal chin crease & $10 / 22$ & $45 \%$ & - & - & $10 / 22$ & $45 \%$ \\
\hline Hypoplastic upper ear helix & $5 / 24$ & $21 \%$ & $3 / 13$ & $23 \%$ & $8 / 37$ & $22 \%$ \\
\hline Prominent finger pads & $2 / 22$ & $9 \%$ & $2 / 10$ & $20 \%$ & $4 / 32$ & $13 \%$ \\
\hline Single palmar crease & $8 / 21$ & $38 \%$ & $5 / 15$ & $33 \%$ & $13 / 36$ & $36 \%$ \\
\hline Clinodactyly & $6 / 21$ & $29 \%$ & $2 / 14$ & $14 \%$ & $8 / 35$ & $23 \%$ \\
\hline Ophthalmological abnormalities & $17 / 21$ & $81 \%$ & $10 / 14$ & $71 \%$ & $27 / 35$ & $77 \%$ \\
\hline Auditory abnormalities & $2 / 11$ & $18 \%$ & $3 / 9$ & $33 \%$ & $5 / 20$ & $25 \%$ \\
\hline Cardiac abnormalities & $9 / 19$ & $47 \%$ & $5 / 7$ & $71 \%$ & $14 / 26$ & $54 \%$ \\
\hline Renal abnormalities & $1 / 9$ & $11 \%$ & $0 / 3$ & $0 \%$ & $1 / 12$ & $8 \%$ \\
\hline Genitourinary tract abnormalities & $12 / 23$ & $52 \%$ & $4 / 6$ & $67 \%$ & $16 / 29$ & $55 \%$ \\
\hline
\end{tabular}

The mean age at last follow-up is 6.48 years, and the median age is 7.25 (range 0.42-23). Two patients died (2/25). Patient 3 died at the age of 16 years due to an aspiration pneumonia. Patient 9 died at the age of 5 months due to complications of a diaphragmatic hernia. The male:female ratio is 20:5.

\section{Neurological phenotype}

Common neurological features are developmental language delay $(23 / 23 ; 100 \%)$, neuromotor delay (NMD) $(22 / 24 ; 92 \%)$ and ID $(23 / 24 ; 96 \%)$. ID is mostly mild to moderate although one-third have severe ID. The severity of the NMD correlates well with ID in this cohort. Of note, two patients (17 and 22) harbouring a frameshift and a splice site mutation, respectively, have a normal neuromotor development, and intellect is normal in patient 22. Behavioural problems (including hyperactivity, aggression, mood lability, obsessions and compulsions) are common (63\%). Autistic features occur in 14 out of 20 patients $(70 \%)$.

Expressive language is more affected than receptive language. One-third of the patients $(8 / 21)$ were able to speak a single word 

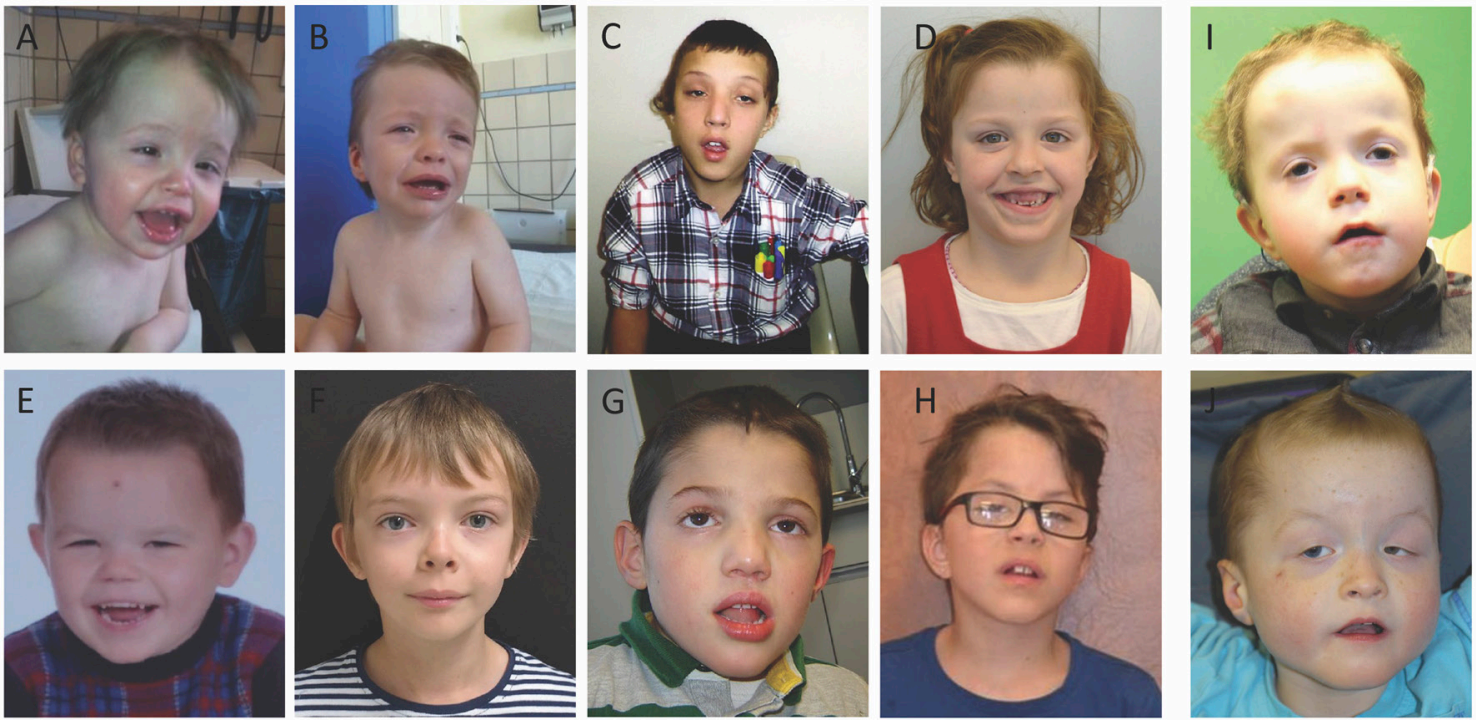

Figure 3 Clinical features of patients with monogenic FOXP1 defects (patient 1 at age 2 years (A), patient 2 at age 2 years (B), patient 6 at age 11 years (C), patient 13 at age 7 years (D), patient 20 at age 3 years (E), patient 22 at age 9 years (F), patient 23 at age 10 years (G), patient 25 at age 8 years $(\mathrm{H})$ ) or interstitial $3 p$ deletions (patient 10 at age 4 years $(\mathrm{I})$, patient 18 at age 5 years $(\mathrm{J})$ ). Note the high and broad forehead, downslanting and/or bent palpebral fissures, ptosis, bulbous nasal tip and pronounced nasolabial folds. Full red lips are most prominent in patients with monogenic defects (A-H).

by the age of 2 years, and about $60 \%$ acquires the ability to speak a few words. Seven patients use short sentences (32\%). Poor grammar (5/7) and articulation problems (9/11) are frequent, and more than half of the patients experience oromotor dysfunction (10/17) and/or feeding difficulties (16/24).

Neurological examination reveals hypotonia in half of the patients (10/21), either generalised (6) or axial (4). Hypertonia is present in six patients $(6 / 21 ; 29 \%)$, being generalised in four. Two patients had peripheral hypertonia in combination with axial hypotonia. Spasticity and contractures (10/19; 53\%) can be present from birth on and can be progressive or transient. Seizures are documented in three patients $(3 / 22 ; 14 \%)$. Half of the patients show structural brain abnormalities (11/23), including cerebral and/or cerebellar atrophy, cortical, subcortical and deep white matter abnormalities, and/or cerebellar abnormalities.

\section{Staturoponderal evolution}

Failure to thrive is reported in eight patients and 30\% (6/20) has a body mass index (BMI) $\leq 10$ th centile at last follow-up. None of them are obese (BMI $\geq 90$ th centile). Nine patients $(43 \%)$ have a head circumference above the 90th centile, and eleven patients have a relative macrocephaly (head circumference more than 25 centiles above the height).

\section{Craniofacial phenotype}

Clinical photographs of some of the patients are shown in figure 3 . The most common craniofacial features in patients with FOXP1 mutations include a high, broad and prominent forehead (96\%), a frontal hair upsweep (42\%), hypertelorism (46\%), downslanting palpebral fissures (58\%), ptosis (67\%), blepharophimosis (17\%), bent palpebral fissures (31\%) and a short nose $(71 \%)$ with a broad tip $(79 \%)$. In most patients, the mouth is wide with full reddish lips (58\%), a pronounced vermilion border (73\%) and downturned corners (58\%). Patients often have an open mouth appearance $(60 \%)$ with pronounced nasolabial folds (42\%). About half of the patients have a prominent chin, mostly with a horizontal crease. Occasionally, unilateral or bilateral hypoplastic upper ear helices (21\%), prominent digital pads (9\%), a single palmar crease (38\%) and clinodactyly (29\%) are reported.

\section{Other organ involvements}

Other commonly affected organ systems are the eye (81\%), heart (47\%) and genitourinary tract (52\%). Ophthalmological abnormalities include strabismus and/or refractive errors, mainly hypermetropia. Optic nerve hypoplasia is reported in one patient. Cardiac defects are minor and often restricted to atrial septal defects. More than half of the boys have unilateral or bilateral cryptorchidism. Four patients had an inguinal hernia. Miscellaneous findings that remain to be confirmed in other patients with FOXP1 mutations are renal malformations (1), diaphragmatic hernia (1), hepatic and bile duct abnormalities (1), transient splenomegaly (1), oesophageal dysmotility (1) and constipation (1), subclinical hypothyroidism (1), hearing impairment (2), developmental dysplasia of the hip (2), spina bifida occulta (1), sacral dimple (2) and anal malformations (1).

\section{Literature review and subgroup analysis}

The previously published cases confirm the higher male:female ratio (14:9) and the major neurological features, including variable NMD, ID, SLI (with more severely affected expressive language), behavioural traits and autistic features. Seventy per cent developed speech, but with poor articulation. Oromotor dysfunction (40\%) and feeding difficulties (73\%) are commonly reported. Hypotonia (50\%) and hypertonia (43\%) are within similar ranges. Spasticity or contractures are reported in 8 out of 10 , and seizures in 4 out of 11 patients (36\%). Anatomical brain defects are present in 10 out of $14(71 \%)$ patients. In 15 patients with reported staturoponderal measurements, failure to thrive is reported in 47\%, and two patients are obese. Absolute macrocephaly or relative macrocephaly is reported in three patients $(3 / 15 ; 20 \%)$. Associated organ systems in the previously reported cases include the eye (refractive disorders (4), strabismus (3), iris coloboma (2) and aniridia (1)), heart (secundum atrial septal defect (5)) and genitourinary tract (cryptorchidism (3)). Three patients have hearing impairment (3/9; 33\%). 
Table 2 Subgroup analysis of monogenic FOXP1 defects versus interstitial deletions

\begin{tabular}{|c|c|c|c|c|c|c|}
\hline \multirow{2}{*}{$\begin{array}{l}\text { Characteristics } \\
\text { Sex (male:female) }\end{array}$} & \multicolumn{2}{|c|}{$3 p$ deletion } & \multicolumn{2}{|c|}{ Monogenic } & \multicolumn{2}{|l|}{ p Value } \\
\hline & & & & & 0.728 & NS \\
\hline Mild/moderate motor delay & $3 / 12$ & $25 \%$ & $27 / 33$ & $82 \%$ & 0.001 & $<0.05$ \\
\hline Severe motor delay & $9 / 12$ & $75 \%$ & $4 / 33$ & $12 \%$ & 0.000 & $<0.05$ \\
\hline Mild/moderate intellectual disability & $3 / 10$ & $30 \%$ & $25 / 33$ & $76 \%$ & 0.019 & $<0.05$ \\
\hline Severe intellectual disability & $7 / 10$ & $70 \%$ & $7 / 33$ & $21 \%$ & 0.007 & $<0.05$ \\
\hline Speech and language delay & $9 / 9$ & $100 \%$ & $33 / 33$ & $100 \%$ & - & - \\
\hline Expressive language delay & $6 / 6$ & $100 \%$ & $23 / 24$ & $96 \%$ & 1.000 & NS \\
\hline Articulation problems & $3 / 3$ & $100 \%$ & $16 / 18$ & $89 \%$ & 1.000 & NS \\
\hline Poor grammar & $0 / 1$ & $0 \%$ & $9 / 10$ & $90 \%$ & 0.182 & NS \\
\hline Oromotor dysfunction & $3 / 4$ & $75 \%$ & $11 / 23$ & $48 \%$ & 0.596 & NS \\
\hline Behavioural difficulties & $1 / 3$ & $33 \%$ & $21 / 29$ & $72 \%$ & 0.224 & NS \\
\hline Autistic features & $4 / 5$ & $80 \%$ & $20 / 27$ & $74 \%$ & 1.000 & NS \\
\hline Abnormal tonicity & $11 / 12$ & $92 \%$ & $15 / 23$ & $65 \%$ & 0.121 & NS \\
\hline Spasticity/contractures & $12 / 13$ & $92 \%$ & $6 / 16$ & $38 \%$ & 0.006 & $<0.05$ \\
\hline Abnormal reflexes & $5 / 9$ & $56 \%$ & $3 / 16$ & $19 \%$ & 0.087 & NS \\
\hline Seizures & $2 / 9$ & $22 \%$ & $5 / 24$ & $21 \%$ & 1.000 & NS \\
\hline Abnormal brain imaging & $9 / 12$ & $75 \%$ & $12 / 25$ & $48 \%$ & 0.166 & NS \\
\hline Abnormal electroencephalography & $0 / 7$ & $0 \%$ & $4 / 14$ & $29 \%$ & 0.255 & NS \\
\hline Failure to thrive & $9 / 11$ & $82 \%$ & $6 / 26$ & $23 \%$ & 0.002 & $<0.05$ \\
\hline Feeding difficulties & $12 / 13$ & $92 \%$ & $12 / 22$ & $55 \%$ & 0.027 & $<0.05$ \\
\hline Obesity & $0 / 7$ & $0 \%$ & $2 / 27$ & $7 \%$ & 1.000 & NS \\
\hline Broad, prominent forehead & $8 / 9$ & $89 \%$ & $26 / 30$ & $87 \%$ & 1.000 & NS \\
\hline Frontal hair upsweep & $3 / 9$ & $33 \%$ & $12 / 29$ & $41 \%$ & 1.000 & NS \\
\hline Hypertelorism & $9 / 12$ & $75 \%$ & $11 / 28$ & $39 \%$ & 0.082 & NS \\
\hline Downslanting palpebral fissures & $4 / 8$ & $50 \%$ & $17 / 30$ & $57 \%$ & 1.000 & NS \\
\hline Bent palpebral fissures & $1 / 4$ & $25 \%$ & $4 / 12$ & $33 \%$ & 1.000 & NS \\
\hline Ptosis & $5 / 7$ & $71 \%$ & $17 / 26$ & $65 \%$ & 1.000 & NS \\
\hline Blepharophimosis & $3 / 9$ & $33 \%$ & $2 / 26$ & $8 \%$ & 0.095 & NS \\
\hline Short nose & $8 / 9$ & $89 \%$ & $19 / 30$ & $63 \%$ & 0.228 & NS \\
\hline Broad nose tip & $6 / 9$ & $67 \%$ & $22 / 30$ & $73 \%$ & 0.693 & NS \\
\hline Pronounced nasolabial folds & $2 / 7$ & $29 \%$ & $9 / 26$ & $35 \%$ & 1.000 & NS \\
\hline Wide mouth with full lips & $1 / 12$ & $8 \%$ & $15 / 26$ & $58 \%$ & 0.005 & $<0.05$ \\
\hline Pronounced vermilion border & $4 / 5$ & $80 \%$ & $12 / 17$ & $71 \%$ & 1.000 & NS \\
\hline Downturned corners of the mouth & $6 / 8$ & $75 \%$ & $12 / 26$ & $46 \%$ & 0.233 & NS \\
\hline Open mouth & $4 / 7$ & $57 \%$ & $14 / 22$ & $64 \%$ & 1.000 & NS \\
\hline Prominent chin & $3 / 5$ & $60 \%$ & $6 / 17$ & $35 \%$ & 0.609 & NS \\
\hline Horizontal chin crease & $3 / 5$ & $60 \%$ & $7 / 17$ & $41 \%$ & 0.624 & NS \\
\hline Hypoplastic upper ear helix & $5 / 11$ & $45 \%$ & $3 / 26$ & $12 \%$ & 0.035 & $<0.05$ \\
\hline Prominent finger pads & $0 / 5$ & $0 \%$ & $4 / 27$ & $15 \%$ & 1.000 & NS \\
\hline Single palmar crease & $6 / 10$ & $60 \%$ & $7 / 26$ & $27 \%$ & 0.119 & NS \\
\hline Clinodactyly & $4 / 9$ & $44 \%$ & $4 / 26$ & $15 \%$ & 0.162 & NS \\
\hline Ophthalmological abnormalities & $9 / 11$ & $82 \%$ & $18 / 24$ & $75 \%$ & 1.000 & NS \\
\hline Auditory abnormalities & $5 / 6$ & $83 \%$ & $0 / 14$ & $0 \%$ & 0.000 & $<0.05$ \\
\hline Cardiac abnormalities & $8 / 11$ & $73 \%$ & $6 / 15$ & $40 \%$ & 0.130 & NS \\
\hline Renal abnormalities & $0 / 3$ & $0 \%$ & $1 / 9$ & $11 \%$ & 1.000 & NS \\
\hline Genitourinary tract abnormalities & $8 / 10$ & $80 \%$ & $8 / 19$ & $42 \%$ & 0.114 & NS \\
\hline
\end{tabular}

NS, not significant.

Using data from the total cohort, we compared the occurrence of the studied phenotypic features between the group with more extended $3 p$ deletions and the group with monogenic FOXP1 defects. Severe NMD, severe ID, feeding difficulties and failure to thrive, spasticity and contractures, and hearing impairment were more frequently encountered in the $3 p$ interstitial deletion group ( $\mathrm{p}<0.05$, table 2 ). Further comparison of phenotypic characteristics between FOXP1 deletions, truncating mutations and splice site mutations and FOXP1 missense mutations showed no difference in severity of NMD and/or ID between both groups.
Neither was there any difference in the other evaluated phenotypic features between both groups, except for the presence of prominent finger pads $(\mathrm{p}<0.05$, table 3$)$.

\section{DISCUSSION}

Mutations in FOXP1 are a generally accepted monogenic cause of ID and SLI. In contrast to FOXP2 mutations they occur de novo. ${ }^{6}$ Our results indicate a loss of function for all tested FOXP1 mutations. Most of the mutations have the potential to 
Table 3 Subgroup analysis of FOXP1 deletions or truncating mutations versus FOXP1 missense mutations

\begin{tabular}{|c|c|c|c|c|c|c|}
\hline Characteristics & Deletio & tion & Miss & tion & $\mathrm{p}$ Value & \\
\hline Sex (male:female) & & & & & 1.000 & NS \\
\hline Mild/moderate motor delay & $22 / 28$ & $79 \%$ & $5 / 5$ & $100 \%$ & 0.556 & NS \\
\hline Severe motor delay & $4 / 28$ & $14 \%$ & $0 / 5$ & $0 \%$ & 1.000 & NS \\
\hline Mild/moderate intellectual disability & $21 / 28$ & $75 \%$ & $4 / 5$ & $80 \%$ & 1.000 & NS \\
\hline Severe intellectual disability & $6 / 28$ & $21 \%$ & $1 / 5$ & $20 \%$ & 1.000 & NS \\
\hline Speech and language delay & $28 / 28$ & $100 \%$ & $5 / 5$ & $100 \%$ & - & - \\
\hline Expressive language delay & $22 / 23$ & $96 \%$ & $1 / 1$ & $100 \%$ & 1.000 & NS \\
\hline Articulation problems & $13 / 14$ & $93 \%$ & $3 / 4$ & $75 \%$ & 0.405 & NS \\
\hline Poor grammar & $9 / 10$ & $90 \%$ & - & - & - & - \\
\hline Oromotor dysfunction & $10 / 20$ & $50 \%$ & $1 / 3$ & $33 \%$ & 1.000 & NS \\
\hline Behavioural difficulties & $17 / 24$ & $71 \%$ & $4 / 5$ & $80 \%$ & 1.000 & NS \\
\hline Autistic features & $17 / 23$ & $74 \%$ & $3 / 4$ & $75 \%$ & 1.000 & NS \\
\hline Abnormal tonicity & $12 / 19$ & $63 \%$ & $3 / 4$ & $75 \%$ & 1.000 & NS \\
\hline Spasticity/contractures & $6 / 16$ & $38 \%$ & - & - & - & - \\
\hline Abnormal reflexes & $3 / 15$ & $20 \%$ & $0 / 1$ & $0 \%$ & 1.000 & NS \\
\hline Seizures & $5 / 22$ & $23 \%$ & $0 / 2$ & $0 \%$ & 1.000 & NS \\
\hline Abnormal brain imaging & $10 / 22$ & $45 \%$ & $2 / 3$ & $67 \%$ & 0.593 & NS \\
\hline Abnormal electroencephalography & $4 / 14$ & $29 \%$ & - & - & - & - \\
\hline Failure to thrive & $6 / 23$ & $26 \%$ & $0 / 3$ & $0 \%$ & 1.000 & NS \\
\hline Feeding difficulties & $12 / 21$ & $57 \%$ & $0 / 1$ & $0 \%$ & 0.455 & NS \\
\hline Obesity & $2 / 24$ & $8 \%$ & $0 / 3$ & $0 \%$ & 1.000 & NS \\
\hline Broad, prominent forehead & $23 / 26$ & $88 \%$ & $3 / 4$ & $75 \%$ & 0.454 & NS \\
\hline Frontal hair upsweep & $11 / 26$ & $42 \%$ & $1 / 3$ & $33 \%$ & 1.000 & NS \\
\hline Hypertelorism & $9 / 25$ & $36 \%$ & $2 / 3$ & $67 \%$ & 0.543 & NS \\
\hline Downslanting palpebral fissures & $14 / 26$ & $54 \%$ & $3 / 4$ & $75 \%$ & 0.613 & NS \\
\hline Bent palpebral fissures & $4 / 11$ & $36 \%$ & $0 / 1$ & $0 \%$ & 1.000 & NS \\
\hline Ptosis & $16 / 24$ & $67 \%$ & $1 / 2$ & $50 \%$ & 1.000 & NS \\
\hline Blepharophimosis & $2 / 24$ & $8 \%$ & $0 / 2$ & $0 \%$ & 1.000 & NS \\
\hline Short nose & $17 / 26$ & $65 \%$ & $2 / 4$ & $50 \%$ & 0.611 & NS \\
\hline Broad nose tip & $20 / 27$ & $74 \%$ & $2 / 3$ & $67 \%$ & 1.000 & NS \\
\hline Pronounced nasolabial folds & $9 / 24$ & $38 \%$ & $0 / 2$ & $0 \%$ & 0.529 & NS \\
\hline Wide mouth with full lips & $14 / 24$ & $58 \%$ & $1 / 2$ & $50 \%$ & 1.000 & NS \\
\hline Pronounced vermilion border & $11 / 15$ & $73 \%$ & $1 / 2$ & $50 \%$ & 0.515 & NS \\
\hline Downturned corners of the mouth & $11 / 24$ & $46 \%$ & $1 / 2$ & $50 \%$ & 1.000 & NS \\
\hline Open mouth & $13 / 20$ & $65 \%$ & $1 / 2$ & $50 \%$ & 1.000 & NS \\
\hline Prominent chin & $5 / 15$ & $33 \%$ & $1 / 2$ & $50 \%$ & 1.000 & NS \\
\hline Horizontal chin crease & $6 / 15$ & $40 \%$ & $1 / 2$ & $50 \%$ & 1.000 & NS \\
\hline Hypoplastic upper ear helix & $2 / 24$ & $8 \%$ & $1 / 2$ & $50 \%$ & 0.222 & NS \\
\hline Prominent finger pads & $2 / 24$ & $8 \%$ & $2 / 3$ & $67 \%$ & 0.049 & $<0.05$ \\
\hline Single palmar crease & $6 / 24$ & $25 \%$ & $1 / 2$ & $50 \%$ & 0.474 & NS \\
\hline Clinodactyly & $4 / 24$ & $17 \%$ & $0 / 2$ & $0 \%$ & 1.000 & NS \\
\hline Ophthalmological abnormalities & $16 / 21$ & $76 \%$ & $2 / 3$ & $67 \%$ & 0.597 & NS \\
\hline Auditory abnormalities & $0 / 13$ & $0 \%$ & - & - & - & - \\
\hline Cardiac abnormalities & $6 / 14$ & $43 \%$ & $0 / 1$ & $0 \%$ & 1.000 & NS \\
\hline Renal abnormalities & $1 / 9$ & $11 \%$ & - & - & - & - \\
\hline Genitourinary tract abnormalities & $6 / 17$ & $35 \%$ & $2 / 2$ & $100 \%$ & 0.164 & NS \\
\hline
\end{tabular}

NS, not significant.

result in premature truncation and nonsense-mediated mRNA decay. ${ }^{33}$ Although western blotting did show the presence of truncated protein if overexpressed from a cDNA plasmid vector, this does not rule out nonsense-mediated mRNA decay in the in vivo situation as this complex process may require the genomic context to be properly activated. Nonetheless, our reporter assay, normalised for transfection efficiency and cell count using an additional Renilla reporter, demonstrates that in case the truncated proteins are produced, their transcriptional repression activity is impaired. A significantly reduced transcriptional repression was also observed for the p.His515Asp missense mutation. This reduced transcriptional repression might be due to impaired DNA-binding of the mutant protein, due to its impact on dimerisation by three-dimensional domain swapping. ${ }^{34-36}$ In contrast, the p.Thr390Ile missense mutation shows normal repression activity compared with wt-FOXP1, although the resulting phenotype is typical for FOXP1-related ID and the mutation occurred de novo. The p.Thr390Ile locates outside the 
DNA-binding FOX domain, in a region where currently only truncating mutations have been identified. We could confirm reduced protein levels for this mutation from Western blot (figure 2A), since the level of protein resulting from the different transfections was normalised according to the Renilla level.

Besides the previously reported link of FOXP1 mutations with ID, SLI and autistic features, our study shows a broader neurological phenotype with more general neurodevelopmental delay (including NMD and ID), spasticity and/or contractures, structural brain abnormalities and epilepsy, as well as involvement of other organ systems including the ocular, cardiovascular and genitourinary systems. Moreover, most patients show a recognisable craniofacial phenotype, that so far has not been routinely recognised. Besides the earlier reported features of relative macrocephaly and a broad and high forehead, ${ }^{20} 2337$ other distinctive features were downslanting and/or bent palpebral fissures, ptosis and/or blepharophimosis, marked nasolabial folds, and a wide mouth with downturned corners and full red lips. The chin becomes more prominent with advancing age. Hand and foot anomalies, such as single palmar crease, clinodactyly and syndactyly are noted, although finger pads, previously considered part of the syndrome, ${ }^{20}$ are only observed in two patients of our cohort.

Previous reports were contradictory on the occurrence of autism. ${ }^{9}{ }^{20}$ In our cohort $70 \%$ of patients present with autistic features, confirming this association. It should however be noted that autism remains a difficult diagnosis in patients with ID and SLI, which might be overdiagnosed in these patients. In about two-thirds other behavioural problems are reported, including hyperactivity, aggression, mood lability, obsessions and compulsions. ${ }^{37}$ Oromotor dysfunction and articulation problems may aggravate the apparent $\mathrm{SLI}^{2037}$ and correlate well with the feeding difficulties (Fisher's exact test $\mathrm{p}=0.006$ ). Feeding difficulties were also associated with failure to thrive (Fisher's exact test $\mathrm{p}<0.001)$. The observation of obesity in two previously reported patients ${ }^{25}$ remains thus far unconfirmed. Remarkably, we observe a male predominance $(34: 14)$. Sex predisposition in autosomal disorders remains largely unexplained, although it has been observed in other entities including Wolf-Hirschhorn syndrome, Brugada syndrome, and long QT syndrome. ${ }^{38-40}$ Fisher's exact test comparing the presence of each studied phenotypic characteristic between male and female revealed no statistically significant difference in the severity of the phenotype between both sexes. Therefore, the observed sex difference cannot be explained by either an increased lethality (less likely) or otherwise a higher occurrence of mild unrecognised cases in women.

Of note, all reported frequencies of the phenotypic characteristics are solely based on available data and did not take into account the amount of missing data. Therefore, the presence of a reporting bias cannot be excluded. Initially, most patients were reported as a $3 \mathrm{p}$ - syndrome, involving FOXP1. ${ }^{41-45}$ However, NGS panel analysis for ID genes and exome analysis clearly shows that monogenic FOXP1 defects are at least twice as frequent as interstitial 3p- deletions. Five FOXP1 mutations were found in a cohort of 2000 patients referred for panel analysis because of epilepsy and ID or autism (DL, personal communication). Therefore, mutations in FOXP1 in this cohort were as frequent as ARID1B and DYRK1A mutations, establishing it as a relatively frequent, but often unrecognised cause of monogenic ID.

No specific genotype-phenotype correlations emerged considering monogenic FOXP1 defects only. Indeed, wide phenotypic variation exists between the four patients who harbour exactly the same c.1573C>T, p. $\left(\operatorname{Arg} 525^{*}\right)$ mutation. Moreover, mild phenotypes were observed in association with both frameshift and splice site mutations. Furthermore, no relevant clinical findings differed significantly between patient groups harbouring missense versus premature truncating mutations. In contrast, patients with extended $3 p$ deletions are at risk of a more severe delay (Fisher's exact test $p<0.05$ ), anterior eye segment abnormalities and hypogenitalism compared with patients with monogenic FOXP1 defects, despite the absence of known disease-modifying candidate genes in the overlapping regions of the deletions. In addition, hearing impairment only occurs in patients with extended $3 p$ deletions (Fisher's exact $\mathrm{p}<0.001$ ) for which MITF, associated with Waardenburg type IIA syndrome (MIM: 193510), emerges as a plausible candidate gene. One patient with hearing impairment did not show a deletion of MITF, but a positional effect cannot be excluded.

The differential diagnosis of SLI is wide (see online supplementary table 3), but the craniofacial 'gestalt' may guide towards an underlying FOXP1 defect and may be helpful in correlating NGS data with clinical presentation.

In case of unclear pathogenicity and absence of sufficient patient material, in vitro functional assessment of variants is straightforward and feasible, showing loss of function either by alternative splicing, reduced repression activity or reduced protein expression.

Patients with FOXP1 defects should be screened for associated organ system involvement including a detailed clinical examination, eye and hearing evaluation (especially in those patients with extended $3 p$ interstitial deletions), echocardiography and ultrasound of the genitourinary tract. Indeed, single nucleotide variants (SNVs) in FOXP1 have recently been associated with congenital anomalies of the kidneys and urinary tract. ${ }^{46}$ An electroencephalogram should be performed if there is any doubt of seizures, and brain MRI should be considered in the presence of epilepsy.

Follow-up should include repeated assessment of the neuromotor development, oromotor development (especially in case of failure to thrive), language development and behavioural problems in order to enable early initiation of therapy. Physiotherapy might be beneficial to prevent progressive contractures in case of spasticity. The management and follow-up of associated organ system involvements should be adjusted to the specific underlying problems and the patient's needs.

In conclusion, we have delineated the FOXP1-related ID syndrome as a recognisable entity that seems to be more frequent than expected based on the rather rare previous case reports. Moreover, the 'gestalt' may help clinicians in interpreting genotype-phenotype correlations.

\section{Author affiliations}

${ }^{1}$ Center for Medical Genetics, Ghent University Hospital, Ghent, Belgium ${ }^{2}$ Department of Pediatrics, Ghent University Hospital, Ghent, Belgium

${ }^{3}$ Montreal Neurological Institute, McGill University, Montreal, Canada

${ }^{4}$ Centre de Génétique humaine, Cliniques Universitaires Saint-Luc, Université catholique de Louvain, Brussels, Belgium

${ }^{5} \mathrm{CHU}$ Sainte-Justine Research Center, Université de Montreal, Montreal, Canada ${ }^{6}$ West Midlands Regional Clinical Genetics Service and Birmingham Health Partners, Birmingham Women's Hospital NHS Foundation Trust, Birmingham Women's Hospital, Edgbaston, UK

${ }^{7}$ Instituto de Genética Médica y Molecular, Hospital Universitario La Paz, IdiPAZ, CIBERER, ISCIII, Madrid, Spain

${ }^{8}$ Centre de Génétique Humaine, Institut de Pathologie et de Génétique, Gosselies, Belgium

${ }^{9}$ NYS Institute for Basic Research in Developmental Disabilities, Staten Island, New York, USA

${ }^{10} \mathrm{Centre}$ for Human Genetics, University Hospital Leuven, Leuven, Belgium

${ }^{11}$ Department of Pediatric Nephrology, University Hospital Leuven, Leuven, Belgium

${ }^{12}$ Beyster Center for Genomics of Psychiatric Diseases, University of California, San Diego, USA 
${ }^{13}$ Departments of Medicine and Neurosciences, UC San Diego School of Medicine, San Diego, USA

${ }^{14}$ Institut für Klinische Genetik, Technische Universität Dresden, Dresden, Deutschland ${ }^{15}$ Department of Pediatrics, Division of Medical Genetics, Stanford University School of Medicine, California, USA

${ }^{16}$ Laboratory of Medical Genetics, Bambino Gesù Children's Hospital, IRCCS, Rome, Italy

${ }^{17}$ Department of Pediatrics and Child Neuropsychiatry, La Sapienza University, Rome, Italy

${ }^{18}$ Institut de Génétique Médicale, Hospital Jeanne de Flandre, Lille, France

${ }^{19}$ Sheffield Clinical Genetics Service, Sheffield Children's Hospital, Sheffield, UK

${ }^{20}$ Genetic Health Service NZ, Wellington, New Zealand

${ }^{21}$ Department of Neurology-Pediatric Neurology, Antwerp University Hospital, Edegem, Belgium

${ }^{22}$ Department of Biology and Medical Genetics, Charles University 2nd Faculty of Medicine and University Hospital Motol, Praque, Czech

${ }^{23}$ Psychiatry Research Laboratory, Prof Dr Alexandru Obregia Clinical Hospital of Psychiatry, Bercini, Romania

Contributors We hereby declare that all authors have contributed to this work: IM and $\mathrm{BC}$ a contributed to the conception and design of the article, data acquisition, analysis and interpretation of the clinical, molecular and functional data, and writing of the manuscript. DL contributed to the conception and design of the article and to the acquisition of clinical and molecular patient data. DR, GAR, FFH, JLM and PAD contributed to the acquisition of the functional data, and analysis and interpretation of these data. NRe, JP, CC, JM, JR, NRa, SGM, PL, MPB, MÁM, StM, VB, SM, NB, AO, OV, MV, TJLdR, DM, JS, KKV, NDD, AKHK, LH, BD, AN, LT, JA, MJP, KN, BCe, A-SS, DP, $\mathrm{MaH}, \mathrm{MiH}, \mathrm{MB}, \mathrm{AD}$ and $\mathrm{BM}$ contributed to the acquisition of clinical and molecular patient data. All authors have approved the manuscript and none have reported a conflict of interest.

Funding $\mathrm{BCa}$ is a Senior Clinical Investigator, funded by Fund for Scientific Research Flanders (FWO). This project was cofunded by FWO project G044615N and Czech grants 00064203 and NF-CZ11-PDP-3-003-2014.

Competing interests None declared.

Patient consent Obtained.

Ethics approval Commissie voor Medische Ethiek Universitair Ziekenhuis Gent.

Provenance and peer review Not commissioned; externally peer reviewed.

Data sharing statement This study makes use of data generated by the DECIPHER Consortium. A full list of centres who contributed to the generation of the data is available from and via email from decipher@sanger.ac.uk. Funding for this project was provided by the Wellcome Trust.

(c) Article author(s) (or their employer(s) unless otherwise stated in the text of the article) 2017. All rights reserved. No commercial use is permitted unless otherwise expressly granted.

\section{REFERENCES}

1 Barnett CP, van Bon BW. Monogenic and chromosomal causes of isolated speech and language impairment. J Med Genet 2015;52:719-29.

2 Newbury DF, Monaco AP. Genetic advances in the study of speech and language disorders. Neuron 2010;68:309-20.

3 Mefford HC, Batshaw ML, Hoffman EP, Genomics HEP. Genomics, intellectual disability, and autism. N Eng/ J Med 2012;366:733-43.

4 Vissers LE, Gilissen C, Veltman JA. Genetic studies in intellectual disability and related disorders. Nat Rev Genet 2016;17:9-18.

5 Condro MC, White SA. Recent advances in the Genetics of Vocal Learning. Comp Cogn Behav Rev 2014;9:75-98.

6 Lai CS, Fisher SE, Hurst JA, Vargha-Khadem F, Monaco AP. A forkhead-domain gene is mutated in a severe speech and language disorder. Nature 2001;413:519-23.

7 Teramitsu I, Kudo LC, London SE, Geschwind DH, White SA. Parallel FoxP1 and FoxP2 expression in songbird and human brain predicts functional interaction. J Neurosci 2004:24:3152-63.

8 Vernes SC, MacDermot KD, Monaco AP, Fisher SE. Assessing the impact of FOXP1 mutations on developmental verbal dyspraxia. Eur J Hum Genet 2009:17:1354-8.

9 Hamdan FF, Daoud H, Rochefort D, Piton A, Gauthier J, Langlois M, Foomani G, Dobrzeniecka S, Krebs MO, Joober R, Lafrenière RG, Lacaille JC, Mottron L, Drapeau P, Beauchamp MH, Phillips MS, Fombonne E, Rouleau GA, Michaud JL. De novo mutations in FOXP1 in cases with intellectual disability, autism, and language impairment. Am J Hum Genet 2010;87:671-8.

10 Kaufmann E, Knöchel W. Five years on the wings of fork head. Mech Dev 1996:57:3-20.

11 Carlsson P, Mahlapuu M. Forkhead transcription factors: key players in development and metabolism. Dev Biol 2002;250:1-23.
12 Chang SW, Mislankar M, Misra C, Huang N, Dajusta DG, Harrison SM, McBride KL, Baker LA, Garg V. Genetic abnormalities in FOXP1 are associated with congenital heart defects. Hum Mutat 2013;34:1226-30

13 Tamura S, Morikawa Y, Iwanishi H, Hisaoka T, Senba E. Expression pattern of the winged-helix/forkhead transcription factor Foxp1 in the developing central nervous system. Gene Expr Patterns 2003;3:193-7.

14 Shu W, Lu MM, Zhang Y, Tucker PW, Zhou D, Morrisey EE. Foxp2 and Foxp1 cooperatively regulate lung and esophagus development. Development 2007;134:1991-2000.

15 Shu W, Yang H, Zhang L, Lu MM, Morrisey EE. Characterization of a new subfamily of winged-helix/forkhead (Fox) genes that are expressed in the lung and act as transcriptional repressors. J Biol Chem 2001;276:27488-97.

16 Wang B, Weidenfeld J, Lu MM, Maika S, Kuziel WA, Morrisey EE, Tucker PW. Foxp1 regulates cardiac outflow tract, endocardial cushion morphogenesis and myocyte proliferation and maturation. Development 2004;131:4477-87.

17 Zhao H, Zhou W, Yao Z, Wan Y, Cao J, Zhang L, Zhao J, Li H, Zhou R, Li B, Wei G, Zhang Z, French CA, Dekker JD, Yang Y, Fisher SE, Tucker HO, Guo X. Foxp1/2/4 regulate endochondral ossification as a suppresser complex. Dev Biol 2015;398:242-54.

18 Thevenon J, Monnier N, Callier P, Dieterich K, Francoise M, Montgomery T, Kjaergaard S, Neas K, Dixon J, Dahm TL, Huet F, Ragon C, Mosca-Boidron AL, Marle N, Duplomb L, Aubriot-Lorton MH, Mugneret F, Vokes SA, Tucker HW, Lunardi J, Faivre L, Jouk PS, Thauvin-Robinet $C$. Delineation of the $3 \mathrm{p} 14.1 \mathrm{p} 13$ microdeletion associated with syndromic distal limb contractures. Am J Med Genet A 2014;164A:3027-34.

19 Carr CW, Moreno-De-Luca D, Parker C, Zimmerman HH, Ledbetter N, Martin CL, Dobyns WB, Abdul-Rahman OA, malformation Cl. Chiari I malformation, delayed gross motor skills, severe speech delay, and epileptiform discharges in a child with FOXP1 haploinsufficiency. Eur J Hum Genet 2010;18:1216-20.

20 Le Fevre AK, Taylor S, Malek NH, Horn D, Carr CW, Abdul-Rahman OA, O'Donnell S, Burgess T, Shaw M, Gecz J, Bain N, Fagan K, Hunter MF. FOXP1 mutations cause intellectual disability and a recognizable phenotype. Am J Med Genet $A$ 2013;161A:3166-75

21 O'Roak BJ, Deriziotis P, Lee C, Vives L, Schwartz JJ, Girirajan S, Karakoc E, Mackenzie AP, Ng SB, Baker C, Rieder MJ, Nickerson DA, Bernier R, Fisher SE, Shendure J, Eichler EE. Exome sequencing in sporadic autism spectrum disorders identifies severe de novo mutations. Nat Genet 2011:43:585-9.

22 Palumbo O, D'Agruma L, Minenna AF, Palumbo P, Stallone R, Palladino T, Zelante $\mathrm{L}$, Carella M. 3p14.1 de novo microdeletion involving the FOXP1 gene in an adult patient with autism, severe speech delay and deficit of motor coordination. Gene 2013:516:107-13.

23 Sollis E, Graham SA, Vino A, Froehlich H, Vreeburg M, Dimitropoulou D, Gilissen C, Pfundt R, Rappold GA, Brunner HG, Deriziotis P, Fisher SE. Identification and functional characterization of de novo FOXP1 variants provides novel insights into the etiology of neurodevelopmental disorder. Hum Mol Genet 2016;25:546-57.

24 Pariani MJ, Spencer A, Graham JM, Rimoin DL. A 785kb deletion of 3p14.1p13, including the FOXP1 gene, associated with speech delay, contractures, hypertonia and blepharophimosis. Eur J Med Genet 2009:52:123-7.

25 Horn D, Kapeller J, Rivera-Brugués N, Moog U, Lorenz-Depiereux B, Eck S, Hempe M, Wagenstaller J, Gawthrope A, Monaco AP, Bonin M, Riess O, Wohlleber E, Illig T, Bezzina CR, Franke A, Spranger S, Villavicencio-Lorini P, Seifert W, Rosenfeld J, Klopocki E, Rappold GA, Strom TM. Identification of FOXP1 deletions in three unrelated patients with mental retardation and significant speech and language deficits. Hum Mutat 2010;31:E1851-E1860.

26 Lozano R, Vino A, Lozano C, Fisher SE, Deriziotis P. A de novo FOXP1 variant in a patient with autism, intellectual disability and severe speech and language impairment. Eur J Hum Genet 2015:23:1702-7.

27 Song $H$, Makino Y, Noguchi E, Arinami T. A case report of de novo missense FOXP mutation in a non-Caucasian patient with global developmental delay and severe speech impairment. Clin Case Rep 2015;3:110-3

28 Tutulan-Cunită AC, Papuc SM, Arghir A, Rötzer KM, Deshpande C, Lungeanu A Búdişteanu M. 3p interstitial deletion: novel case report and review. J Child Neurol 2012:27:1062-6.

29 Talkowski ME, Rosenfeld JA, Blumenthal I, Pillalamarri V, Chiang C, Heilbut A, Ernst C, Hanscom C, Rossin E, Lindgren AM, Pereira S, Ruderfer D, Kirby A, Ripke S, Harris DJ, Lee JH, Ha K, Kim HG, Solomon BD, Gropman AL, Lucente D, Sims K, Ohsumi TK, Borowsky ML, Loranger S, Quade B, Lage K, Miles J, Wu BL, Shen Y, Neale B, Shaffer LG, Daly MJ, Morton CC, Gusella JF. Sequencing chromosomal abnormalities reveals neurodevelopmental loci that confer risk across diagnostic boundaries. Cell 2012;149:525-37.

30 Srivastava S, Cohen JS, Vernon H, Barañano K, McClellan R, Jamal L, Naidu S, Fatemi A. Clinical whole exome sequencing in child neurology practice. Ann Neurol 2014;76:473-83.

31 Church DM, Stotler CJ, Rutter JL, Murrell JR, Trofatter JA, Buckler AJ. Isolation of genes from complex sources of mammalian genomic DNA using exon amplification. Nat Genet 1994:6:98-105.

32 Piton A, Jouan L, Rochefort D, Dobrzeniecka S, Lachapelle K, Dion PA, Gauthier J, Rouleau GA. Analysis of the effects of rare variants on splicing identifies alterations in GABAA receptor genes in autism spectrum disorder individuals. Eur J Hum Genet 2013;21:749-56. 
33 Hug N, Longman D, Cáceres JF. Mechanism and regulation of the nonsense-mediated decay pathway. Nucleic Acids Res 2016;44:1483-95.

34 Chu YP, Chang CH, Shiu JH, Chang YT, Chen CY, Chuang WJ. Solution structure and backbone dynamics of the DNA-binding domain of FOXP1: insight into its domain swapping and DNA binding. Protein Sci 2011;20:908-24.

35 Medina E, Córdova C, Villalobos P, Reyes J, Komives EA, Ramírez-Sarmiento CA, Babul J. Three-Dimensional domain swapping changes the Folding mechanism of the Forkhead domain of FoxP1. Biophys J 2016;110:2349-60.

36 Perumal K, Dirr HW, Fanucchi S. A single amino acid in the Hinge Loop Region of the FOXP forkhead domain is significant for Dimerisation. Protein J 2015:34:111-21

37 Horn D. Mild to Moderate Intellectual disability and Significant speech and language deficits in patients with FOXP1 deletions and mutations. Mol Syndromol 2012;2:213-6.

38 Coles K, Mackenzie M, Crolla J, Harvey J, Starr J, Howard F, Jacobs P. A complex rearrangement associated with sex reversal and the Wolf-Hirschhorn syndrome: a cytogenetic and molecular study. J Med Genet 1992;29:400-6.

39 Di Diego JM, Cordeiro JM, Goodrow RJ, Fish JM, Zygmunt AC, Pérez GJ, Scornik FS, Antzelevitch C. Ionic and cellular basis for the predominance of the Brugada syndrome phenotype in males. Circulation 2002;106:2004-11.

40 Imboden M, Swan H, Denjoy I, Van Langen IM, Latinen-Forsblom PJ, Napolitano C, Fressart V, Breithardt G, Berthet M, Priori S, Hainque B, Wilde AA, Schulze-Bahr E, Feingold J, Guicheney P. Female predominance and transmission distortion in the long-QT syndrome. N Engl J Med 2006;355:2744-51.
41 Wieczorek D, Bolt J, Schwechheimer K, Gillessen-Kaesbach G. A patient with interstitial deletion of the short arm of chromosome 3 (pter-->p21.2::p12-->qter) and a CHARGE-like phenotype. Am J Med Genet 1997;69:413-7.

42 Schinzel A, Gundelfinger R, Dutly F, Baumer A, Binkert F. A 5-year-old girl with interstitial deletion of 3p14: clinical, psychologic, cytogenetic, and molecular studies. Am J Med Genet 1998;77:302-5.

43 Petek E, Windpassinger C, Simma B, Mueller T, Wagner K, Kroisel PM. Molecular characterisation of a $15 \mathrm{mb}$ constitutional de novo interstitial deletion of chromosome $3 p$ in a boy with developmental delay and congenital anomalies. J Hum Genet 2003;48:283-7.

44 Schwarzbraun T, Ofner L, Gillessen-Kaesbach G, Schaperdoth B, Preisegger KH, Windpassinger C, Wagner K, Petek E, Kroisel PM. A new 3p interstitial deletion including the entire MITF gene causes a variation of Tietz/Waardenburg type IIA syndromes. Am J Med Genet A 2007;143A:619-24.

45 Lalli C, Galasso C, Lo Castro A, Nardone AM, Di Paolo A, Curatolo P. Interstitial deletion of a proximal $3 \mathrm{p}$ : a clinically recognisable syndrome. Brain Dev 2007:29:312-6.

46 Bekheirnia MR, Bekheirnia N, Bainbridge MN, Gu S, Coban Akdemir ZH, Gambin T, Janzen NK, Jhangiani SN, Muzny DM, Michael M, Brewer ED, Elenberg E, Kale AS, Riley AA, Swartz SJ, Scott DA, Yang Y, Srivaths PR, Wenderfer SE, Bodurtha J, Applegate CD, Velinov M, Myers A, Borovik L, Craigen WJ, Hanchard NA, Rosenfeld JA, Lewis RA, Gonzales ET, Gibbs RA, Belmont JW, Roth DR, Eng C, Braun MC, Lupski JR, Lamb DJ. Whole-exome sequencing in the molecular diagnosis of individuals with congenital anomalies of the kidney and urinary tract and identification of a new causative gene. Genet Med 2017;19. 


\section{Erratum: FOXP1-related intellectual disability syndrome: a recognisable entity}

Meerschaut I, Rochefort D, Revençu N, et al. FOXP1-related intellectual disability syndrome: a recognisable entity. Journal of Medical Genetics 2017;54:613-623.

In the original article, the authors noted four mutation annotation errors in figure $1 \mathrm{~B}$ and supplementary table 1 . Correction of the mistakes in the annotations have no impact on the results and conclusions of this article. The authors apologise for all possible inconveniences due to these errors.

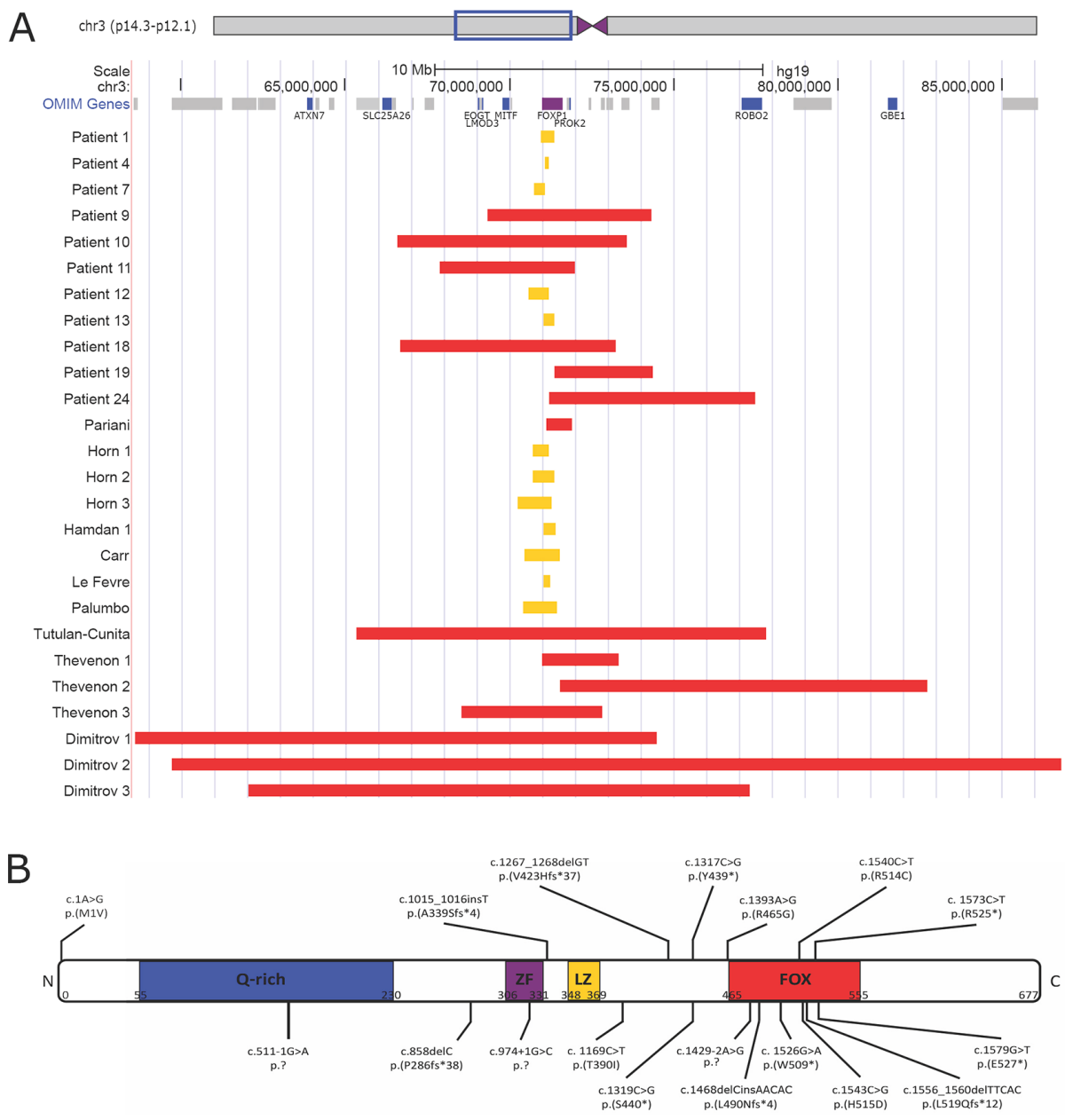

The corrected annotations are as follows:

- In patient 5 the correct c. and p. notations for the mutation are c.858delC and p.(R288Gfs*37), instead of c.858delC and p.(P286fs*38)

- In patient 17 the correct c. and p. notations for the mutation are c.1462delCinsAACAC and p.(L488Nfs*4), instead of c.1468delCinsAACAC and p.(L490Nfs*4)

- In patient 21 the correct c. and p. notations for the mutation are c.1556_1560delTTCAC and p.(L519Qfs*10), instead of c.1556_1560delTTCAC and p.(L519Qfs*12)

- For the patient reported in O'Roak et al the correct c. and p. notations for the mutation are c.1014_1015insA and p.(A339Sfs*4), instead of c.1015_1016insT and p.(A339Sfs*4)

These mistakes were corrected in figure $1 \mathrm{~B}$ and the online supplementary table 1 .

(C) Article author(s) (or their employer(s) unless otherwise stated in the text of the article) 2017. All rights reserved. No commercial use is permitted unless otherwise expressly granted.

J Med Genet 2018;55:72. doi:10.1136/jmedgenet-2017-104579corr1 
Correction to: Correction: FOXP1-related intellectual disability

syndrome: a recognisable entity

The text of the erratum article (jmedgenet-2017-104579corr $1^{1}$ ) is correct, but unfortunately we included the wrong figure. The correct figure is the following:

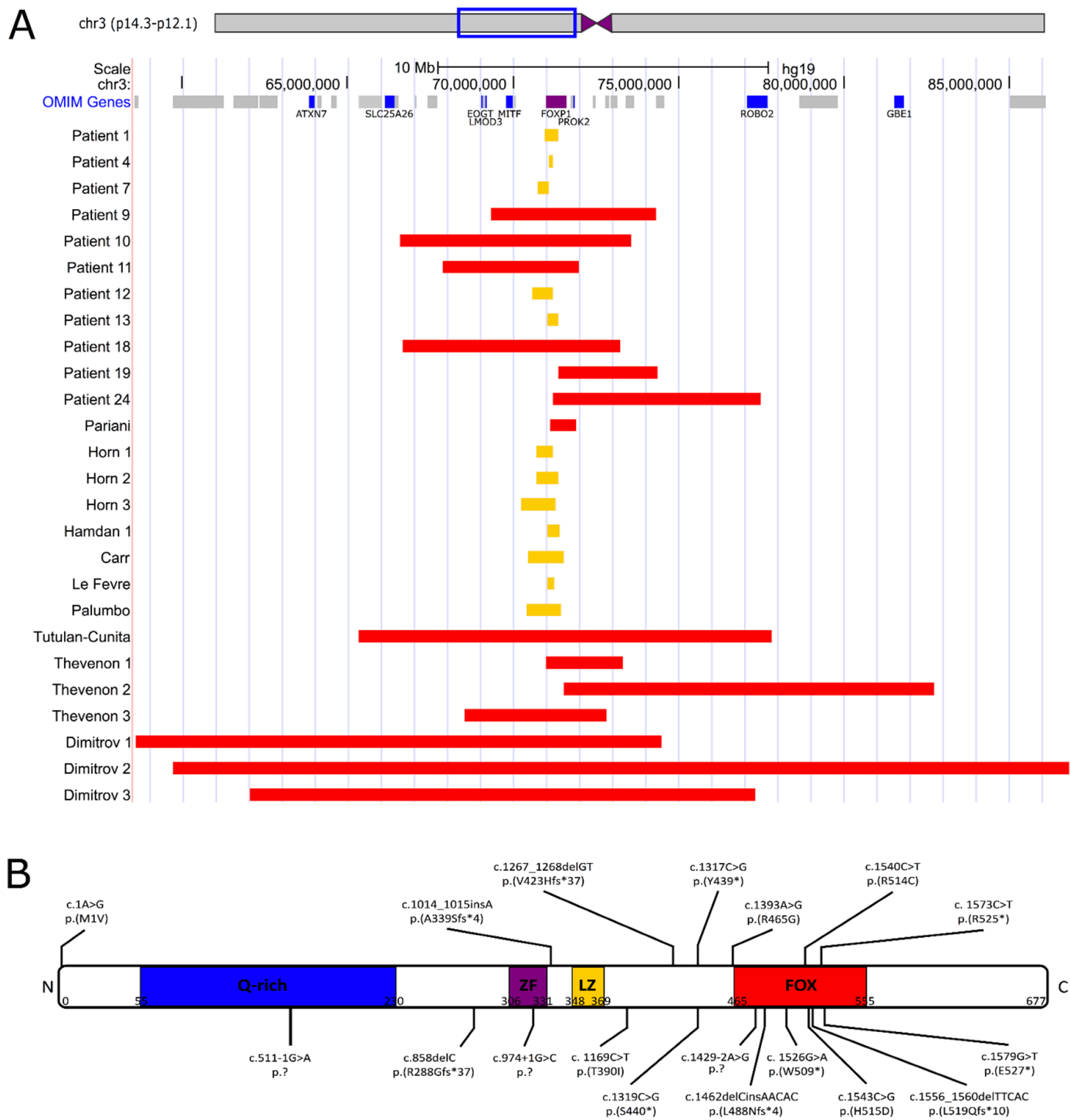

(C) Article author(s) (or their employer(s) unless otherwise stated in the text of the article) 2018. All rights reserved. No commercial use is permitted unless otherwise expressly granted.

J Med Genet 2018;55:214. doi:10.1136/jmedgenet-2017-104579corr2

Check for updates

REFERENCE

1. Correction: FOXP1-related intellectual disability syndrome: a recognisable entity. J Med Genet 2018;55:72-3. 